\title{
BMJ Open Performance of primary care in different healthcare facilities: a cross-sectional study of patients' experiences in Southern Malawi
}

\author{
Luckson Dullie, ${ }^{1}$ Eivind Meland, ${ }^{2}$ Øystein Hetlevik, ${ }^{3}$ Thomas Mildestvedt, ${ }^{2}$ \\ Stephen Kasenda, ${ }^{\oplus 4}$ Constance Kantema, ${ }^{5}$ Sturla Gjesdal ${ }^{\circledR}$
}

To cite: Dullie L, Meland E, Hetlevik $\emptyset$, et al. Performance of primary care in different healthcare facilities: a cross-sectional study of patients' experiences in Southern Malawi. BMJ Open 2019;9:e029579. doi:10.1136/ bmjopen-2019-029579

\section{- Prepublication history and} additional material for this paper are available online. To view please visit the journal (http:// dx.doi.org/10.1136/bmjopen2019-029579).

Received 1 February 2019 Revised 31 May 2019 Accepted 7 June 2019

\section{Check for updates}

(c) Author(s) (or their employer(s)) 2019. Re-use permitted under CC BY-NC. No commercial re-use. See rights and permissions. Published by BMJ.

${ }^{1}$ Global Public Health and Primary Care, Universitetet i Bergen Det medisinskodontologiske fakultet, Bergen, Norway

${ }^{2}$ Department of Family Medicine, School of Family Medicine and Public Health, University of Malawi, Malawi

${ }^{3}$ Partners in Health, Malawi ${ }^{4}$ Department of Health, Blantyre District Health Office, Blantyre, Malawi

${ }^{5}$ Department of Education, Lilongwe Urban Education Office, Lilongwe, Malawi

Correspondence to Dr Luckson Dullie; Idullie@pih.org

\section{ABSTRACT}

Objective In most African countries, primary care is delivered through a district health system. Many factors, including staffing levels, staff experience, availability of equipment and facility management, affect the quality of primary care between and within countries. The purpose of this study was to assess the quality of primary care in different types of public health facilities in Southern Malawi.

Study design This was a cross-sectional quantitative study.

Setting The study was conducted in 12 public primary care facilities in Neno, Blantyre and Thyolo districts in July 2018.

Participants Patients aged $\geq 18$ years, excluding the severely ill, were selected to participate in the study. Primary outcomes We used the Malawian primary care assessment tool to conduct face-to-face interviews. Analysis of variance at 0.05 significance level was performed to compare primary care dimension means and total primary care scores. Linear regression models at $95 \% \mathrm{Cl}$ were used to assess associations between primary care dimension scores, patients' characteristics and healthcare setting.

Results The final number of respondents was 962 representing $96.1 \%$ response rate. Patients in Neno hospitals scored 3.77 points higher than those in Thyolo health centres, and 2.87 higher than those in Blantyre health centres in total primary care performance. Primary care performance in health centres and in hospital clinics was similar in Neno (20.9 vs $19.0, p=0.608$ ) while in Thyolo, it was higher at the hospital than at the health centres (19.9 vs $15.2, p<0.001)$. Urban and rural facilities showed a similar pattern of performance.

Conclusion These results showed considerable variation in experiences among primary care users in the public health facilities in Malawi. Factors such as funding, policy and clinic-level interventions influence patients' reports of primary care performance. These factors should be further examined in longitudinal and experimental settings.

\section{BACKGROUND}

Primary care is first contact, continuous, comprehensive, coordinated care that is provided to populations undifferentiated
Strengths and limitations of this study

- This study is the first attempt in Malawi to measure the quality of primary care in different types of health facilities based on patients' experiences.

- This study used a culturally adapted and locally validated measurement tool that has been widely used globally.

- There might have been potential for selection, response and recall bias as the data were collected from patients in a clinical setting; however, the faceto-face interviews provided opportunity for follow-up clarifying questions to minimise the recall bias.

by gender, disease or organ system. ${ }^{1}$ Strong evidence suggests that effective primary care is associated with improved equity and access to healthcare services, reduced hospitalisations and better cost effectiveness. ${ }^{2-5}$ Primary care is also considered as a vehicle for accelerating progress towards universal health coverage. ${ }^{67}$

In most African countries, primary care is delivered through a district health system. At primary-level facilities, healthcare workers (HCWs) and community health workers (CHWs) provide integrated preventive and curative services to a geographically defined population under the supportive supervision of a district hospital and district health management team and with active participation of the community. ${ }^{8}$

The quality of primary care between and within countries is affected by many factors. In a recent study in several African countries, staffing levels, staff experience, availability of equipment and facility management were some factors that accounted for variation in the quality of primary care. ${ }^{9}$ In the US healthcare setting, it was found that health centres generally achieved higher quality of primary care while primary care in hospitals 
was associated with less continuity. ${ }^{10}$ Similar results were found in a Chinese study which showed that community health centres provided better-quality primary care when compared with secondary and tertiary healthcare facilities. ${ }^{11}$ In a South African study, public rural and urban primary care users had similar experiences of quality. This was attributed to standardised service packages and treatment guidelines within the sector. ${ }^{12}$

Malawi has in the recent past registered notable progress particularly in HIV/AIDS and child health indicators. ${ }^{13}$ However, significant persisting challenges include poor access to services ${ }^{14}$ inequity and inadequate financial risk protection. ${ }^{15} 16$ The new 2017-2022 national health sector strategic plan (HSSP II) seeks to achieve universal health coverage and improved patient satisfaction. ${ }^{16}$ As no studies have been conducted in Malawi to compare patients' experience of quality of primary care in the different settings of the public health sector, the results of this study contribute to the HSSP II goals. The study is also a baseline of the experiences of patients with regard to the performance of primary care in the southern Malawi and thus provides a basis for quality improvement in service delivery.

The purpose of this study was to assess the quality of primary care in different types of public health facilities and to discuss implications of the findings in the context of using the district health system model to achieve universal health coverage in the South West health zone in Malawi. Study objectives were to compare primary care performance between districts, between rural and urban health centres and between hospital clinics and health centres and to assess the association between primary care performance and characteristics of the primary care facilities. The null hypothesis for the study was that there is no difference in performance of primary care between the different types of healthcare facilities.

\section{MATERIALS AND METHODS}

\section{Study design}

This was an observational quantitative cross-sectional study and we used the STROBE cross-sectional reporting guidelines ${ }^{17}$ to report the results.

\section{Sampling procedure}

The study was conducted in 12 facilities in three districts in the South West health zone in July and August 2018.

The South West health zone includes seven districts serving a population of about 3 million. Two districts were purposefully selected: Neno because it receives the highest per capital funding in Malawi ${ }^{18}$ and Blantyre because it has an urban population. The remaining five districts were assigned numbers $1-5$ by using the alphabetical order of their first letters. The third participating district was selected by using a computer random number generator.

The two hospitals in Neno and the district hospital in Thyolo were purposefully selected on the basis of being the only public hospitals offering primary care within the study districts. All public health centres in each district were assigned numbers in ascending order by using the alphabetical order of their first letters. Participating health centres were selected by using a computer random number generator so that each district had four study health facilities. The study population included adult patients attending outpatient care in public health centres and hospitals in the selected districts. Study participants were at least 18 years of age, must have used the facility for at least 6 months and must have visited the facility for at least three times. Patients with acute illness or with severe mental health disorders were excluded to allow them receive the urgent care that they needed.

There was no booking system for outpatients in the facilities where patients were seen. Patients reported to the outpatient clinics directly and received services on first come first served basis. Each interviewer was expected to conduct 12 interviews per day based on prior experience with the questionnaire. Potential subjects were identified through a pre-calculated interval which was based on the expected duration of each interview and the number of waiting patients at the beginning of each day. The interviewer approached the potential subject to administer the screening questions and the written consent. If the potential subject did not consent, the next potential subject was approached using the same procedure described above.

\section{Sample size determination}

The sample size was calculated based on findings from a previous paper that compared primary care assessment set of tools (PCAT) scores between patients in county, secondary and tertiary hospitals and rural health and community health centres. ${ }^{11}$ The minimum sample size of this study was estimated as 900 with a $95 \%$ CI and a power of $80 \%$ and considering $2.5 \%$ incomplete or missing data.

\section{Measurement instrument and data collection}

The PCAT are among the most widely used tools internationally in primary healthcare assessment. ${ }^{19}$ The PCAT aims at a global assessment of primary care organisation and its performance in the core dimensions of accessibility, comprehensiveness, coordination and continuity and accountability. The tool was originally developed by Starfield et al..$^{20}$ It has since been adapted and validated for use in numerous countries, which allows for comparison of primary care performance in different settings. ${ }^{21-25}$

We used the Malawian version of the PCAT (PCAT-Mw) whose validation was reported in another paper. ${ }^{26}$ The PCAT-Mw is a multi-item multidimension questionnaire that measures primary care performance covering core dimensions of primary care (attached as online supplementary file: validated PCAT-Mw items). The tool has 29 items measuring primary care performance in seven dimensions: first contact access (three items), communication continuity of care (four items), relational continuity of care (four items), coordination (three items), comprehensiveness of services available (six items), 
comprehensiveness of services provided (six items) and community orientation (three items). First contact access is here defined as the manner in which services are organised to accommodate access whenever needed and ensure patient satisfaction. Continuity of care entails the existence of a regular source of care and the longitudinal relationship between primary care providers and patients, in terms of accommodation of patient's needs and preferences, such as communication and respect for patients. Coordination of care reflects the ability of primary care providers to facilitate and support patients to navigate use of other levels of healthcare when needed. Comprehensiveness of primary care services represents the range of services available in primary care to meet patients' healthcare needs. A distinction is made between services that are available and those that are actually provided. Community orientation defines the extent to which the primary care providers understand and address priority health problems in a particular community with evidence of community participation.

Items are scored on a four-point Likert scale, with 1 indicating 'definitely not', 2 indicating 'probably not', 3 representing 'probably' and 4 representing 'definitely'. Additionally, there are questions to identify the usual primary care facility the patient uses and the patient's sociodemographic data.

Data collection was done through face-to-face interviewer-administered questionnaire from eligible patients in July 2018. Research assistants with prior interviewing experience received a 2-day refresher training before the start of data collection interviews.

\section{Conceptual framework of the study}

The study uses the Starfield primary care quality theoretical model ${ }^{27}$ in which the primary care system includes its organisation, governance, available financial and human resources and its information systems. The primary care dimensions form its process of care including accessibility, continuity of care, coordination of care, comprehensiveness of services and community orientation. The outcomes of primary care include improved health status, user evaluation, health behaviour change, equity, efficiency and safety. The interplay between the primary care system and its process to bring about the desired outcomes is modified by environmental and patient characteristics. In this study, the dimensions of primary care are used as the process indicators for quality of primary care. Patients' positive experience reflecting acceptable performance in the dimensions of primary care is indicative of a high-quality delivery system.

\section{Study variables}

Study outcome measures were mean scores of each primary care dimension and the total primary care score. Independent variables included sociodemographic characteristics: age, sex, education, employment status of the patient and/or the head of the household, patient's disability status; healthcare measures: acute or chronic presentation, duration of contact with facility, estimated time taken to get to the facility, frequency of visits in the past 2 years, satisfaction with care and self-rated health status. Data were also collected on district characteristics such as location (rural/urban), catchment population, number of HCWs, number of community HCWs and estimated per capita health funding.

\section{Data entry and statistical analysis}

Data analysis was done using the IBM SPSS Statistics V.25.0.0 (2017) package. For consistency with methods used in PCAT studies in other countries, a mid-scale value of 2.5 was assigned to 'not sure' answers while the mean item score was used for missing data. ${ }^{21} 222528$

First, $\mathrm{X}^{2}$ analyses were applied to compare sociodemographic, healthcare and health characteristics of patients in the different types of facilities. Primary care dimension mean scores were derived by dividing the sum of the item means by the number of items in the dimension. A score $\geq 3$ was considered 'acceptable to good performance' and $<3$ as 'poor performance'. ${ }^{12} 29$ Total primary care was calculated as the sum of all dimension mean scores. Next, independent sample t-tests and analysis of variance were performed to compare performance of primary care dimensions in different types of healthcare facilities. Multiple linear regression models were then used to assess the association between types of facility and performance of primary care dimensions after controlling for patients' sociodemographic, healthcare and health characteristics.

\section{Patient and public involvement}

We did not involve patients and the public in the design of the study.

\section{Ethical approval and consent to participate}

District Health Officers gave permission for the study in their respective districts. Study participants provided written consent.

\section{RESULTS}

This paper presents results from 962 completed questionnaires out of 1001 potential respondents who were approached representing $96.1 \%$ response rate. Those who declined cited lack of time to participate. Missing data accounted for approximately $1.2 \%$ of all data.

\section{District characteristics}

Table 1 shows that Neno had the highest density of both primary HCWs and CHWs followed by Blantyre for HCWs and Thyolo for CHWs, respectively. With regards to funding, Neno received about three times as much total per capita healthcare funding as Thyolo and Blantyre, respectively, during 2017-2018 financial year.

Demographic and healthcare characteristics of participants Table 2 compares the distribution of patient characteristics for the five types of healthcare settings. Sixty-four 
Table 1 Structural and organisational characteristics of primary care facilities in South West health zone, Malawi, in JulyAugust 2018

\begin{tabular}{|c|c|c|c|c|c|c|}
\hline Facility & Type of facility & Location & $\begin{array}{l}\text { Catchment } \\
\text { population }\end{array}$ & $\begin{array}{l}\text { Number of } \\
\text { HCWs* } \\
\text { (per } 1000 \text { pop) }\end{array}$ & $\begin{array}{l}\text { Number of } \\
\text { CHWst } \\
\text { (per } 1000 \text { pop) }\end{array}$ & $\begin{array}{l}\text { District per capita } \\
\text { health funding in } \\
\text { US\$ per year }\end{array}$ \\
\hline Neno & & & & & & 60 \\
\hline 1 & Hospital & Rural & 20711 & $9(0.4)$ & $143(6.9)$ & \\
\hline 2 & Hospital & Rural & 11284 & $4(0.4)$ & $112(9.9)$ & \\
\hline 3 & Health centre & Rural & 14433 & $3(0.2)$ & $98(6.8)$ & \\
\hline 4 & Health centre & Rural & 8936 & $4(0.4)$ & $58(6.5)$ & \\
\hline Thyolo & & & & & & 22 \\
\hline 5 & Hospital & Rural & 51318 & $21(0.4)$ & $24(0.5)$ & \\
\hline 6 & Health centre & Rural & 19444 & $1(0.1)$ & $14(0.7)$ & \\
\hline 7 & Health centre & Rural & 47092 & $8(0.2)$ & $29(0.6)$ & \\
\hline 8 & Health centre & Rural & 52782 & $7(0.1)$ & $22(0.4)$ & \\
\hline Blantyre & & & & & & 18 \\
\hline 9 & Health centre & Urban & 78561 & $25(0.3)$ & $37(0.5)$ & \\
\hline 10 & Health centre & Urban & 79675 & $33(0.4)$ & $41(0.5)$ & \\
\hline 11 & Health centre & Urban & 135726 & $31(0.2)$ & $44(0.3)$ & \\
\hline 12 & Health centre & Urban & 145821 & $23(0.2)$ & $46(0.3)$ & \\
\hline
\end{tabular}

${ }^{*} \mathrm{HCW}$ comprised nurses/nurse-midwives/medical assistants/clinical officers.

†CHWs comprised health surveillance assistants and community health volunteers on stipend.

CHWs, community health workers; HCWs, healthcare workers.

percent of primary care visits were from females and $>80 \%$ of patients were between 18 and 45 years of age. Among rural patients, $81 \%$ were affiliated to their primary care facilities for $>4$ years compared with $55 \%$ among urban patients. Fifteen percent of respondents in Blantyre had 5 years or less of education compared with $37 \%$ among Thyolo health centres respondents and $45 \%$ in Neno health centres. About $60 \%$ of patients in Neno walked for more than 1 hour to their facility compared with $48 \%$ in Thyolo and 17\% in Blantyre.

\section{Primary care performance by district}

Table 3 compares primary care performance at the district level through total PCAT-Mw and individual dimension mean scores. Patients in Neno reported a significantly higher total primary care performance at $20.3 \quad(\mathrm{n}=303$, $95 \%$ CI 20.0 to 20.6) compared with both Thyolo and Blantyre at 16.8 ( $\mathrm{n}=358,95 \%$ CI 16.4 to 17.2$)$ and 16.4 $(\mathrm{n}=301,95 \%$ CI 16.1 to 16.7$)$, respectively ( $\mathrm{p} \leq 0.01)$. This same difference was found in all but one (relational continuity) of the primary care dimensions measured. In Neno, acceptable performance was reported in first contact access (3.1), communication continuity (3.6), coordination (3.1) and community orientation (3.2). Poor performance was reported in relational continuity (1.9), comprehensiveness of services available and provided, at 2.7 each.

There was no significant difference between Thyolo and Blantyre with regard to total primary care performance. Patients in Thyolo reported significantly higher scores relative to patients in Blantyre in relational continuity (2.0 vs $1.6, \mathrm{p}<0.01)$ and comprehensiveness of services provided ( 2.5 vs $2.3, \mathrm{p}<0.05)$ but patients from Blantyre reported higher scores in first contact access (2.5 vs 2.3, $\mathrm{p}<0.05)$ and comprehensiveness of services available (2.2 vs 2.0, $\mathrm{p}<0.05)$. Both Blantyre and Thyolo had acceptable performance score (3.4) in communication continuity. Poor performance was reported in other primary care dimensions in both districts. The lowest scores were reported in coordination (1.8 and 1.7).

\section{Primary care performance in rural and urban facilities}

Table 4 shows the bivariate results comparing primary care dimension scores in health centres to highlight differences between urban and rural settings. Patients in Neno reported a significantly higher total primary care performance at $20.9(\mathrm{n}=152,95 \%$ CI 20.4 to 21.4) compared with both Thyolo and Blantyre at $16.8(\mathrm{n}=226,95 \% \mathrm{CI}$ 14.8 to 15.6$)$ and $16.4(\mathrm{n}=301,95 \%$ CI 16.1 to 16.7$)$, respectively $(\mathrm{p} \leq 0.01)$. Neno health centres also reported better performance in all of the primary care dimensions. In Neno, acceptable performance was reported in first contact access (3.0), communication continuity (3.6), coordination (3.6) and community orientation (3.1). Poor performance was reported in relational continuity (2.3), comprehensiveness of services available (2.4) and comprehensiveness of services provided at 2.9. Blantyre and Thyolo health centres reported acceptable performance only in communication continuity (3.4). Both 
Table 2 Demographic, socioeconomic and health measures of the patients attending clinics in South West health zone, Malawi, in July and August 2018, shown by type of facility

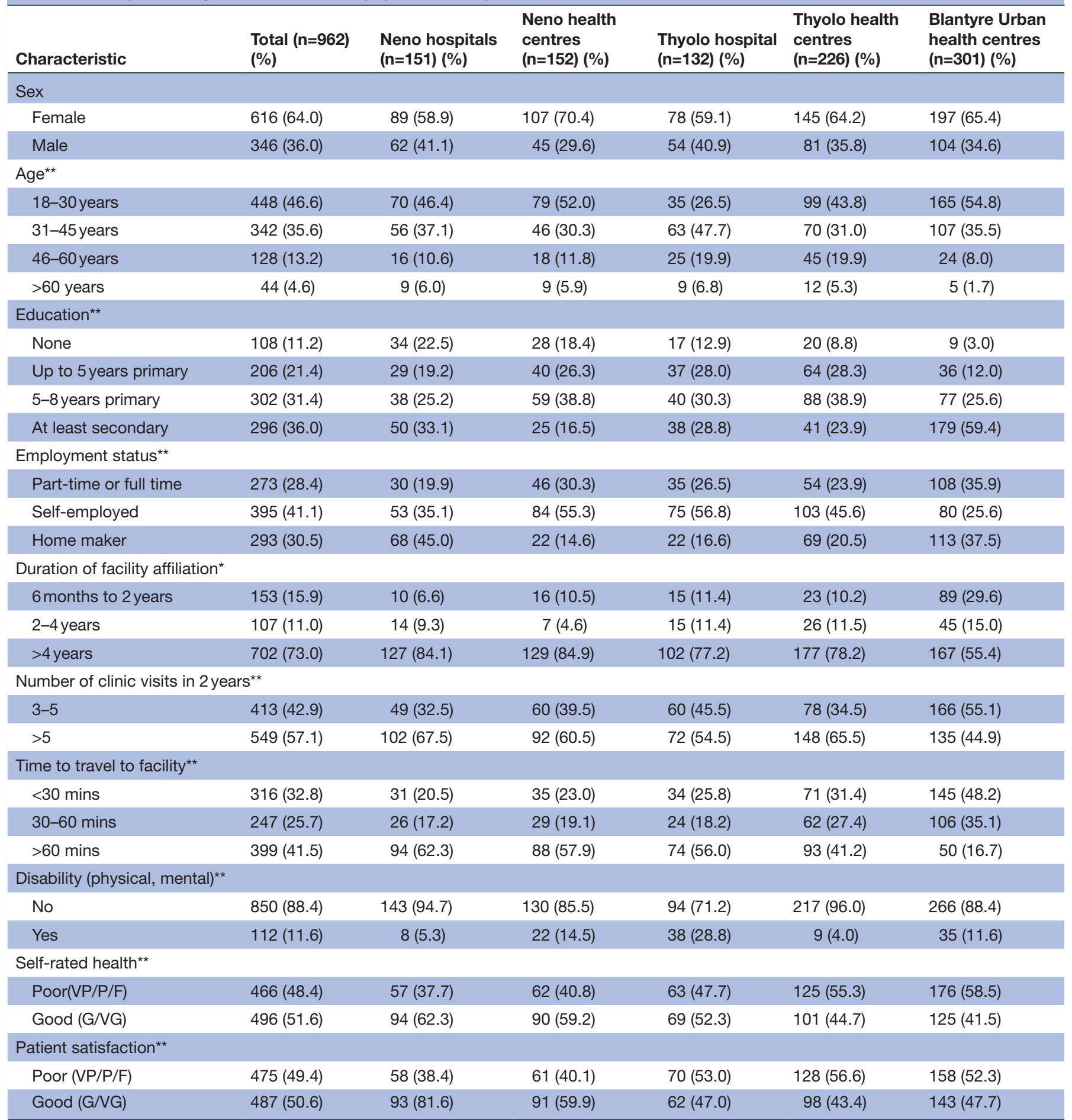

${ }^{\star} \mathrm{P}<0.05$, Duration of facility affiliation. ${ }^{* *} \mathrm{P}<0.01$, based on $\mathrm{X}^{2}$ test of difference across healthcare settings.

districts reported poor performance in the other dimensions and coordination was lowest (1.7).

Primary care dimension scores in hospital and health centre clinics

Table 5 shows results of primary care dimension scores compared between hospitals and health centre clinics. Because of the performance differences between the districts as noted above, Neno and Thyolo are compared separately. There is no public hospital in Blantyre.

Health centres and hospitals performed equally well in both districts in communication continuity and equally poorly in comprehensiveness of services provided. Hospitals performed better than health centres in both districts in community orientation and comprehensiveness of services available. Thyolo hospital also performed better 


\begin{tabular}{|c|c|c|c|c|}
\hline Characteristic & Total $(95 \% \mathrm{Cl})$ & Neno $(95 \% \mathrm{Cl})$ & Thyolo $(95 \% \mathrm{Cl})$ & Blantyre $(95 \% \mathrm{Cl})$ \\
\hline Sample size & 962 & 303 & 358 & 301 \\
\hline First contact-access & 2.6 (2.5 to 2.7 ) & $3.1(3.0 \text { to } 3.2)^{\star \star}$ & $2.3(2.2 \text { to } 2.4)^{\star \star \#}$ & $2.5(2.4 \text { to } 2.6)^{\star \star} \#$ \\
\hline Communication continuity & 3.4 (3.3 to 3.5$)$ & $3.6(3.5 \text { to } 3.7)^{\star}$ & $3.4(3.3 \text { to } 3.5)^{\star}$ & $3.4(3.3 \text { to } 3.5)^{*}$ \\
\hline Relational Continuity & 1.8 (1.7 to 1.9$)$ & $1.9(1.8 \text { to } 2.0)^{\star \star}$ & 2.0 (1.9 to 2.1$) \# \#$ & $1.6(1.5 \text { to } 1.7)^{\star \star} \# \#$ \\
\hline Coordination & 2.0 (1.8 to 2.2$)$ & $3.1(2.8 \text { to } 3.4)^{\star \star}$ & $1.8(1.5 \text { to } 2.1)^{\star \star}$ & $1.7(1.5 \text { to } 1.9)^{\star \star}$ \\
\hline \multicolumn{5}{|l|}{ Comprehensiveness } \\
\hline Services available & 2.3 (2.2 to 2.4$)$ & $2.7(2.6 \text { to } 2.8)^{\star \star}$ & $2.0(1.9 \text { to } 2.1)^{\star \star} \#$ & $2.2(2.1 \text { to } 2.3)^{\star \star} \#$ \\
\hline Services provided & 2.5 (2.4 to 2.6$)$ & $2.7(2.6 \text { to } 2.8)^{\star \star}$ & $2.5(2.4 \text { to } 2.6)^{\star \star} \#$ & $2.3(2.2 \text { to } 2.4)^{\star \star \#}$ \\
\hline Community orientation & 2.9 (2.8 to 3.0$)$ & $3.2(3.1 \text { to } 3.3)^{\star \star}$ & $2.8(2.7 \text { to } 2.9)^{\star \star}$ & $2.7(2.6 \text { to } 2.8)^{\star \star}$ \\
\hline Total PCAT-Mw score & 17.5 (17.3 to 17.7$)$ & $20.3(20.0 \text { to } 20.6)^{\star \star}$ & $16.8(16.4 \text { to } 17.2)^{\star \star}$ & $16.4(16.1 \text { to } 16.7)^{\star \star}$ \\
\hline
\end{tabular}

Based on ANOVA Bonferroni post-hoc means test.

${ }^{*} \mathrm{P}<0.05,{ }^{\star *} \mathrm{P}<0.01$ comparing Neno and Thyolo and Blantyre.

$\# \mathrm{P}<0.05, \# \mathrm{P}<0.01$ comparing Thyolo and Blantyre.

ANOVA, analysis of variance; PCAT-Mw, Malawian version of the primary care assessment set of tools.

in first contact access, relational continuity, coordination and total PCAT-Mw scores than health centres. Coordination and relational continuity were reported better in health centres than hospitals in Neno. The only difference between Neno and Thyolo hospitals was a better relational continuity in Thyolo.

Figure 1 shows a radar chart showing dimension performance according to the different settings. The figure shows that the differences between the contexts were most evident in first contact access and coordination comprehensiveness of services available. Neno health centres performed better than the other facilities in coordination.
Multivariate analyses of primary care dimension mean scores Table 6 presents the results of the multivariable linear regression analyses used to assess the association between facility characteristics and primary care total and dimension performance mean scores after controlling for patients' sociodemographic and healthcare and health characteristics.

Using Neno hospitals as the reference, the coefficient for Thyolo health centres was -3.77 , and -2.87 for the health centres in Blantyre in total primary care. Thus, patients in Neno hospitals would have on average an estimated 3.77 points greater score than those in Thyolo

Table 4 Primary care dimension mean scores in South West health zone, Malawi, in July and August 2018, comparing rural and urban health facilities

\begin{tabular}{|c|c|c|c|c|}
\hline Characteristic & $\begin{array}{l}\text { Total } \\
(95 \% \mathrm{Cl})\end{array}$ & $\begin{array}{l}\text { Neno } \\
\text { Health centres } \\
\text { (Rural) } \\
(95 \% \mathrm{Cl}) \\
\end{array}$ & $\begin{array}{l}\text { Thyolo health } \\
\text { centres (Rural) } \\
\text { (95\% Cl) }\end{array}$ & $\begin{array}{l}\text { Blantyre Urban Health } \\
\text { centres } \\
(95 \% \mathrm{Cl})\end{array}$ \\
\hline Sample size & 962 & 152 & 226 & 301 \\
\hline First contact-access & 2.6 (2.4 to 2.7 ) & $3.0(2.9 \text { to } 3.1)^{\star \star}$ & $1.8(1.7 \text { to } 1.9)^{\star \star \# \# ~}$ & 2.5 (2.4 to 2.6$)^{\star \star \# \# ~}$ \\
\hline Communication continuity & 3.4 (3.3 to 3.5 ) & 3.6 (3.5 to 3.7 ) & 3.4 (3.3 to 3.5$)$ & 3.4 (3.3 to 3.5 ) \\
\hline Relational continuity & 1.8 (1.7 to 1.9$)$ & $2.3(2.1 \text { to } 2.5)^{\star \star}$ & $1.8(1.7 \text { to } 1.9)^{\star \star} \#$ & $1.6(1.5 \text { to } 1.6)^{\star \star} \#$ \\
\hline Coordination & 2.0 (1.8 to 2.2 ) & $3.6(3.3 \text { to } 3.9)^{\star \star}$ & $1.7(1.4 \text { to } 2.0)^{\star \star}$ & $1.7(1.5 \text { to } 1.9)^{\star \star}$ \\
\hline \multicolumn{5}{|l|}{ Comprehensiveness } \\
\hline Services available & 2.3 (2.2 to 2.4 ) & $2.4(2.3 \text { to } 2.5)^{\star *}$ & $1.4(1.3 \text { to } 1.5)^{\star \star \# \# ~}$ & $2.2(2.1 \text { to } 2.3)^{\star \star \# \# ~}$ \\
\hline Services provided & 2.5 (2.4 to 2.6 ) & $2.9(2.8 \text { to } 3.0)^{\star \star}$ & $2.5(2.4 \text { to } 2.6)^{\star \star} \#$ & $2.3(2.2 \text { to } 2.4)^{\star \star} \#$ \\
\hline Community orientation & 2.9 (2.8 to 3.0$)$ & $3.1(3.0 \text { to } 3.2)^{\star}$ & $2.6(2.4 \text { to } 2.7)^{\star}$ & $2.7(2.6 \text { to } 2.8)^{\star}$ \\
\hline Total PCAT-Mw score & $17.5(17.3$ to 17.7$)$ & $20.9(20.4 \text { to } 21.4)^{\star \star}$ & $15.2(14.8 \text { to } 15.6)^{\star \star \# \# ~}$ & $16.4(16.1 \text { to } 16.7)^{\star \star \# \# ~}$ \\
\hline
\end{tabular}

Based on ANOVA Bonferroni post-hoc means test.

${ }^{*} \mathrm{P}<0.05$, Duration of facility affiliation. ${ }^{*} \mathrm{P}<0.01$ comparing Neno and Thyolo and Blantyre.

$\# \mathrm{P}<0.05$, \#\#P<0.01 comparing Thyolo and Blantyre.

ANOVA, analysis of variance; PCAT-Mw, Malawian version of the primary care assessment set of tools. 
Table 5 Primary care dimension mean scores among patients attending outpatient clinics in South West health zone, Malawi, in July and August 2018, shown by hospital and health centre clinics.

\begin{tabular}{|c|c|c|c|c|c|c|}
\hline Characteristic & $\begin{array}{l}\text { Neno } \\
\text { hospitals } \\
\text { (SE) }\end{array}$ & $\begin{array}{l}\text { Neno } \\
\text { Health } \\
\text { centres (SE) }\end{array}$ & $P$ value & $\begin{array}{l}\text { Thyolo } \\
\text { hospital } \\
\text { (SE) }\end{array}$ & $\begin{array}{l}\text { Thyolo health } \\
\text { centres (SE) }\end{array}$ & $P$ value \\
\hline First contact-access & $3.1(0.05)$ & $3.0(0.05)$ & 0.308 & $3.1(0.07)$ & $1.8(0.05)$ & $<0.001^{* *}$ \\
\hline Communication continuity & $3.6(0.05)$ & $3.6(0.05)$ & 0.816 & $3.5(0.07)$ & $3.4(0.06)$ & 0.371 \\
\hline \multicolumn{7}{|l|}{ Comprehensiveness } \\
\hline Services available & $3.1(0.05)$ & $2.4(0.05)$ & $<0.001^{* *}$ & $3.1(0.06)$ & $1.4(0.04)$ & $<0.001^{* *}$ \\
\hline Services provided & $2.7(0.08)$ & $2.9(0.07)$ & 0.085 & $2.5(0.06)$ & $2.5(0.07)$ & 0.753 \\
\hline Community orientation & $3.3(0.07)$ & $3.1(0.06)$ & $0.025^{\star}$ & $3.2(0.08)$ & $2.6(0.06)$ & $<0.001^{* *}$ \\
\hline
\end{tabular}

Based on ANOVA Bonferroni post-hoc means test.

${ }^{*} \mathrm{P}<0.05,{ }^{*} \mathrm{P}<0.01$ comparing hospitals and health centres;

$\# \mathrm{P}<0.05$ when Neno and Thyolo hospitals were compared.

ANOVA, analysis of variance; PCAT-Mw, Malawian version of the primary care assessment set of tools.

health centres, and 2.87 greater score than those in Blantyre health centres. The variables studied explained $30 \%$ of the variances observed with regard to total primary care scores.

With respect to dimensions, similar results were seen in coordination of care, first contact access and comprehensiveness of services available. In these dimensions, the studied variables explained $22.4 \%, 37.7 \%$ and $54.4 \%$ of the variances observed.

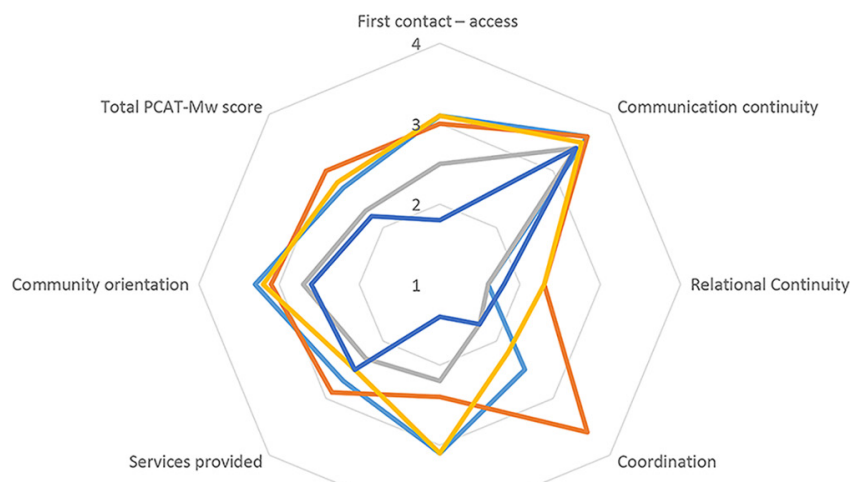

Services available

$$
\text { Neno hospitals } \quad \text { Neno Health centers } \longrightarrow \text { Blantyre Health centers }
$$

Figure 1 Mean primary care attribute scores among patients attending outpatient clinics in South West health zone, Malawi, in July and August 2018, shown by hospitals and health centre clinics. HC, health centre; PCAT-Mw, Malawian version of the primary care assessment set of tools.

\section{DISCUSSION}

This study assessed the performance of primary care as experienced and reported by patients in different types of public health facilities in three districts in the South West health zone in Malawi. We used an internationally recognised and locally validated tool, PCAT. When performance was compared among the three districts, Neno achieved a significantly higher total primary care score than Blantyre and Thyolo, respectively. Patients in Neno also reported acceptable scores in first contact access, communication continuity of care, coordination and community orientation compared with good performance in only one dimension (communication continuity of care) in Thyolo and Blantyre.

These results can partly be explained by the significantly higher per capita health funding that Neno currently receives compared with the other districts. Similar conclusions were made when Neno was compared with other districts in programme performance outcomes in maternal and child health ${ }^{18}$ and HIV care indicators ${ }^{30}$ in previous studies.

Another related possible explanation is the low HCWpatient and CHW-patient ratios observed in Neno. Staffing levels were among factors that were identified to have affected quality of primary care in a study in several African countries including Malawi. ${ }^{9}$ Achieving Malawi's HSSP II goals of better health outcomes and patient satisfaction will therefore require more investment to increase healthcare spending above the national average of 40 US\$ per capita which is the lowest in the South African Development Community region ${ }^{16}$ since it is known that increase in public healthcare spending has a long-lasting impact in low-resource communities ${ }^{31}$ and is associated with better health outcomes. ${ }^{32}$ 
Table 6 Linear regression models assessing association between sociodemographic, healthcare, health factors, primary care dimension mean scores and types of health facilities with unstandardised beta values among 962 patients attending outpatient clinics in South West zone, Malawi, in July-August 2018

\begin{tabular}{|c|c|c|c|c|c|c|c|c|}
\hline & $\begin{array}{l}\text { Total Primary } \\
\text { care }\end{array}$ & $\begin{array}{l}\text { First contact } \\
\text { access }\end{array}$ & $\begin{array}{l}\text { Communication } \\
\text { continuity }\end{array}$ & $\begin{array}{l}\text { Continuity } \\
\text { relational }\end{array}$ & Coordination & $\begin{array}{l}\text { Services } \\
\text { available }\end{array}$ & $\begin{array}{l}\text { Services } \\
\text { provided }\end{array}$ & $\begin{array}{l}\text { Community } \\
\text { orientation }\end{array}$ \\
\hline Reference & $17.12(0.55)$ & $3.10(0.14)$ & $3.47(0.15)$ & $1.77(0.16)$ & $2.96(0.51)$ & $3.05(0.11)$ & $2.39(0.19)$ & $3.37(0.17)$ \\
\hline \multicolumn{9}{|l|}{ Sex (Ref: M)† } \\
\hline Female & $-0.29(0.20)$ & $0.04(0.05)$ & $-0.09(0.05)$ & $-0.11(0.06)^{*}$ & $0.25(0.21)$ & $-0.09(0.04)^{*}$ & $-0.08(0.07)$ & $0.03(0.06)$ \\
\hline \multicolumn{9}{|c|}{ Age (Ref: $18-30$ years) $\dagger$} \\
\hline $45-60$ years & $-0.35(0.30)$ & $-0.01(0.07)$ & $-0.31(0.08)^{\star \star}$ & $0.09(0.09)$ & $0.10(0.28)$ & $0.05(0.06)$ & $-0.12(0.10)$ & $-0.05(0.09)$ \\
\hline$>60$ years & $0.07(0.45)$ & $0.09(0.11)$ & $-0.04(0.12)$ & $0.13(0.13)$ & $-0.46(0.47)$ & $-0.01(0.09)$ & $-0.18(0.16)$ & $0.09(0.14)$ \\
\hline \multicolumn{9}{|c|}{ Education (Ref: $0-5$ years primary) $\dagger$} \\
\hline Primary 6-8 & $0.34(0.23)$ & $0.07(0.06)$ & $0.12(0.06)^{\star}$ & $0.02(0.07)$ & $0.14(0.22)$ & $-0.01(0.05)$ & $0.15(0.08)$ & $-0.002(0.07)$ \\
\hline Sec school & $0.47(0.25)$ & $0.07(0.06)$ & $0.004(0.07)$ & $0.09(0.07)$ & $0.18(0.22)$ & $-0.04(0.05)$ & $0.15(0.09)$ & $0.20(0.08)^{\star}$ \\
\hline$>60$ mins & $-0.51(0.23)^{\star}$ & $-0.12(0.06)^{\star}$ & $-0.09(0.06)$ & $-0.19(0.07)^{\star \star}$ & $-0.37(0.21)$ & $0.05(0.05)$ & $0.04(0.08)$ & $-0.21(0.07)^{\star \star}$ \\
\hline \multicolumn{9}{|l|}{ Disability (Ref: No)† } \\
\hline Yes & $0.06(0.29)$ & $-0.09(0.07)$ & $0.05(0.08)$ & $-0.03(0.08)$ & $-0.24(0.24)$ & $0.03(0.06)$ & $0.18(0.10)$ & $-0.08(0.09)$ \\
\hline \multicolumn{9}{|c|}{ Employment (Ref: Yes)† } \\
\hline No & $-0.14(0.21)$ & $0.04(0.05)$ & $0.14(0.06)^{\star}$ & $-0.19(0.06)^{\star \star}$ & $0.08(0.20)$ & $0.04(0.04)$ & $-0.03(0.07)$ & $-0.14(0.07)^{\star}$ \\
\hline \multicolumn{9}{|c|}{ Visits frequency in 2 years (Ref: $3-5) \dagger$} \\
\hline$>5$ times & $0.16(0.19)$ & $-0.09(0.05)$ & $0.13(0.05)^{\star}$ & $-0.16(0.06)^{\star *}$ & $-0.21(0.17)$ & $0.02(0.04)$ & $0.18(0.07)$ & $0.07(0.06)$ \\
\hline \multicolumn{9}{|c|}{ Self-rated health (Ref: VP/P/F)† } \\
\hline G/VG & $0.43(0.19)^{\star}$ & $0.05(0.05)$ & $0.05(0.05)$ & $0.10(0.06)$ & $0.08(0.17)$ & $0.06(0.04)$ & $0.09(0.07)$ & $0.18(0.06)^{\star *}$ \\
\hline \multicolumn{9}{|c|}{ Satisfaction (Ref: VP/P/F)† } \\
\hline Thyolo HCs & $3.77(0.30)^{\star *}$ & $-1.35(0.07)^{\star \star}$ & $-0.12(0.08)$ & $0.22(0.09)^{*}$ & $-0.89(0.32)^{\star \star}$ & $-1.64(0.06)^{\star \star}$ & $-0.18(0.11)^{\star}$ & $-0.70(0.09)^{\star \star}$ \\
\hline Thyolo hospital & $0.36(0.35)$ & $-0.03(0.09)$ & $-0.03(0.09)$ & $0.68(0.10)^{\star *}$ & $-0.37(0.36)$ & $0.04(0.07)$ & $-0.18(0.12)$ & $-0.11(0.11)^{\star \star}$ \\
\hline Blantyre HCs & $2.87(0.31)^{\star *}$ & $-0.69(0.08)^{\star \star}$ & $-0.17(0.08)^{\star}$ & $-0.04(0.09)$ & $-1.10(0.31)^{\star \star}$ & $-0.83(0.06)^{\star *}$ & $-0.45(0.11)^{\star \star}$ & $-0.70(0.10)^{\star \star}$ \\
\hline $\mathrm{R}^{2}$ & $30.0 \%$ & $37.7 \%$ & $9.0 \%$ & $15.7 \%$ & $22.4 \%$ & $54.4 \%$ & $5.7 \%$ & $14.6 \%$ \\
\hline
\end{tabular}

tUnadjusted linear regression models.

fLinear regression models adjusted for sociodemographic, healthcare and health characteristics of patients.

${ }^{*} \mathrm{P} \leq 0.05 ;{ }^{* *} \mathrm{P} \leq 0.01$.

$\mathrm{HCs}$, health centres; HF, health facility.

Performance of primary care in health centres was compared with highlighted differences between urban and rural settings. The better performance reported in Neno health centres is probably due to the same factors as described above. Blantyre and Thyolo districts had similar per capita funding and HCW-patient and CHWpatient ratio. The pattern of performance is also similar across all primary care dimensions although differences in scores among individual dimensions resulted in higher total primary care in the urban facilities. The similar pattern of performance is likely because of the just noted similarities in their primary care inputs. In addition to having similar available resources, standardised protocols and clinical guidelines are used by the HCWs who provide primary care and would have received similar training. Results of a South African study on organisation and performance of primary care in the Cape Town region, where standardised protocols were used, also did not show a significant difference in experiences of patients from rural and urban settings. ${ }^{12}$ This probably implies that equitable distribution of resources is more 
important than the setting per se in the quality of services that patients experience.

We also compared primary care experiences among patients attending health centre and hospital clinics. This was done by using facilities in Neno and Thyolo. Health centres play an important gate-keeping role that is essential to well-functioning health systems. In this study, health centres from Thyolo scored lower than the hospital clinic in total primary care and all of the individual dimensions except communication continuity of care. In most districts, the peripheral facilities face more acute challenges than the district hospital. A qualitative assessment of primary healthcare in Malawi found that some of the challenges that peripheral facilities experienced were inadequacy of supplies, shortage of personnel, poor quality of infrastructures and unavailable transport and communication equipment. ${ }^{33}$ The same study also found that health partners preferred district-level to health centre-level implementation thereby exacerbating uneven distribution of resources. The poor performance in health centres may also be a result of people's lack of trust in primary care providers and their services.

In Neno, total primary care was similar at the hospitals and health centres. There were, however, differences in performances between the two levels among the individual dimensions with health centres doing better in relational continuity and coordination of care. Smaller facilities tend to favour relational continuity and coordination of care. ${ }^{34}$ Funding and staffing levels are likely not the only factors that impact on patients' reporting of primary care performance. Further prospective studies could explore the reasons for the similarities in primary care performance between the hospital clinics (Neno and Thyolo) and health centres in Neno.

The differences in primary performance reported by patients from different types of health facilities held true in this study irrespective of the patients' sociodemographic and healthcare characteristics. Among the primary care dimensions, first contact access and comprehensiveness of services available contributed more to the observed variation. The factors that were assessed explained $37.7 \%$ and $54.4 \%$ of the variances in first contact access and comprehensiveness of services available, respectively. This is a suggestion of some order of importance among the dimensions at least as shown in this study. Utilisation, coordination and continuity of services can effectively take place only when people have access to the services that they need. WHO states in its report on universal health coverage that the first objective is that everybody should be able to access a full range of quality health services. ${ }^{35}$ A systematic review of the literature on the dimensions of primary care by Kringos et al concludes that a hierarchy of importance could be observed. The hierarchy consisted of access to primary care services, the comprehensiveness of services available and provided, continuity and coordination of care. ${ }^{36}$ The improvement of access to services that people need is therefore a reasonable step towards improving quality of primary care.
Access and comprehensiveness of services largely depend on the facility infrastructure, availability of medical supplies and adequate supply of appropriately trained primary HCWs (including CHWs). On the other hand, continuity of care, coordination and community orientation depend on the local clinic operations. ${ }^{37}$ Improving primary care in Malawi will therefore require both policy and clinic level interventions. The results of this study also showed that there was no significant difference in communication continuity across the different types of facilities. This dimension also performed well across all facilities. A possible explanation for this might be the similar preservice training that primary care providers receive regarding patient-provider communication. Further studies could explore the role of preservice training interventions in affecting the quality of primary care delivered.

The strength of this study lies in the use of a culturally adapted and locally validated tool that has been used widely globally to assess performance of primary care from patients' perspective in many different settings. Additionally, it is the first time that this kind of study has been undertaken in the three districts. The results of this study, therefore, provide insight into patients' perspective of primary care performance thereby complimenting clinical health outcome measures in evaluating quality of health services.

The study had a number of limitations. First, there is potential for bias in the data. Recall bias could occur as the patients were asked to provide information not only from current but also from historical experience. The face-to-face interview partly minimised recall bias through clarifying questions whenever that was necessary. Potential for response bias was possible because data collection was done onsite during a clinic visit. Selection bias might have resulted from excluding those who were acutely ill, frail or had severe mental illness and interviewing only patients who attended clinics. Second, a cross-sectional study is an efficient way of obtaining a large sample. However, it is not possible to make causal inferences from the analysis. Third, this was a study of patient experiences of primary care and not of disease-specific clinical outcomes. Further studies could assess correlations between clinical outcomes and patient experiences of care and the extent to which patient experiences predict later health outcomes. Fourth, there could be unmeasured confounding factors that might affect patients' experience of primary care other than those studied.

\section{CONCLUSION}

Despite these limitations, the findings of this study are helpful in providing insight into the performance of primary care in different types of public facilities in Malawi. This paper showed that there is considerable variation in experiences among primary care users in the public health facilities in Malawi. Factors such as funding, policy and clinic-level interventions influence patients' 
reports of primary care performance. These factors should be further examined in longitudinal and experimental settings.

Acknowledgements The authors thank the participants in the survey for taking part in this study.

Contributors LD conceived, designed and carried out the study, the data analysis and drafting of the paper. EM took part in the development of the study, the analysis, interpretation of data and critically revised the paper. CK, SK and SG took part in the development of the study, supported interpretation of the results and critically revised the paper. CK supervised the data collection. ØH and TM critically revised the paper. All authors read and approved the final paper.

Funding Funding for the study was provided by PIH and the University of Bergen. The principal investigator and corresponding author is employed by $\mathrm{PIH}$ and is a PhD fellow at the University of Bergen.

Competing interests None declared.

Patient consent for publication Not required.

Ethics approval Ethical approval was provided by National Health Sciences Research Committee (NHSRC) of Malawi (18/03/1993).

Provenance and peer review Not commissioned; externally peer reviewed. Data sharing statement Data are available in a public, open access repository. Open access This is an open access article distributed in accordance with the Creative Commons Attribution Non Commercial (CC BY-NC 4.0) license, which permits others to distribute, remix, adapt, build upon this work non-commercially, and license their derivative works on different terms, provided the original work is properly cited, appropriate credit is given, any changes made indicated, and the use is non-commercial. See: http://creativecommons.org/licenses/by-nc/4.0/.

\section{REFERENCES}

1. Starfield B. Is primary care essential? The Lancet 1994;344:1129-33.

2. Franks P, Fiscella K. Primary care physicians and specialists as personal physicians. Health care expenditures and mortality experience. J Fam Pract 1998;47:p105-9.

3. Shi L, Starfield B. Primary care, income inequality, and self-rated health in the United States: a mixed-level analysis. Int J Health Serv 2000;30:541-55.

4. Shi L. The relationship between primary care and life chances. $J$ Health Care Poor Underserved 1992;3:321-35.

5. Starfield B, Shi L, Macinko J. Contribution of primary care to health systems and health. Milbank Q 2005;83:457-502.

6. Rao M, Pilot E. The missing link--the role of primary care in global health. Glob Health Action 2014;7:23693.

7. Stigler FL, Macinko J, Pettigrew LM, et al. No universal health coverage without primary health care. Lancet 2016;387:1811.

8. Segall M. District health systems in a neoliberal world: a review of five key policy areas. Int J Health Plann Manage 2003;18(Suppl 1):S5-S26.

9. Kruk ME, Chukwuma A, Mbaruku G, et al. Variation in quality of primary-care services in Kenya, Malawi, Namibia, Rwanda, Senegal, Uganda and the United Republic of Tanzania. Bull World Health Organ 2017;95:408-18.

10. Shi L, Starfield B, Xu J, et al. Primary care quality: community health center and health maintenance organization. South Med J 2003;96:787-95.

11. Hu R, Liao Y, Du Z, et al. Types of health care facilities and the quality of primary care: a study of characteristics and experiences of Chinese patients in Guangdong Province, China. BMC Health Serv Res 2016;16:335.

12. Bresick GF, Sayed A-R, Le Grange C, et al. Western Cape Primary Care Assessment Tool (PCAT) study: Measuring primary care organisation and performance in the Western Cape Province, South Africa (2013). African Journal of Primary Health Care \& Family Medicine 2016;8:a1057.

13. Government of Malawi: Ministry of Finance Economic Planning and Development. Malawi. Millennium Development Goals Report 2014.
http://www.mw.undp.org/content/dam/malawi/docs/general/UNDP_ MW_EDP_MDG_book_final.pdf (accessed on 28 Apr 2018).

14. Abiiro GA, Mbera GB, De Allegri M. Gaps in universal health coverage in Malawi: a qualitative study in rural communities. BMC Health Serv Res 2014;14:234.

15. Zere $\mathrm{E}$, Moeti $\mathrm{M}$, Kirigia J, et al. Equity in health and healthcare in Malawi: analysis of trends. BMC Public Health 2007;7:78.

16. Malawi Government Ministry of Health. Health Sector Strategic Plan II 2017 - 22: Lilongwe, 2017. www.health.gov.mw/index.php/ policies-strategies?download=47:hssp-ii-final (Accessed $21 \mathrm{Jul}$ 2017).

17. von Elm E, Altman DG, Egger M, et al. Strengthening the Reporting of Observational Studies in Epidemiology (STROBE) statement: guidelines for reporting observational studies. BMJ 2007;335:806-8.

18. WHO. Health sector resource mapping: increasing access to information for decision making. 2013 http://www.who.int/pmnch/ media/events/2013/resource_mapping.pdf (Accessed 20 Jan 2018).

19. Fracolli LA, Gomes MF, Nabão FR, et al. Primary health care assessment tools: a literature review and metasynthesis. Cien Saude Colet 2014;19:4851-60.

20. Starfield B, Xu J, Shi L. Validating the Adult Primary Care Assessment Tool. The Journal of Family Practice 2001:50:161-75.

21. Yang H, Shi L, Lebrun LA, et al. Development of the Chinese primary care assessment tool: data quality and measurement properties. Int $J$ Qual Health Care 2013;25:92-105.

22. Lee JH, Choi YJ, Sung NJ, et al. Development of the Korean primary care assessment tool--measuring user experience: tests of data quality and measurement performance. Int $J$ Qual Health Care 2009;21:103-11.

23. Berra S, Rocha KB, Rodríguez-Sanz M, et al. Properties of a short questionnaire for assessing primary care experiences for children in a population survey. BMC Public Health 2011;11:285

24. Haggerty JL, Burge F, Beaulieu MD, et al. Validation of instruments to evaluate primary healthcare from the patient perspective: overview of the method. Healthc Policy 2011;7:31-46.

25. Bresick G, Sayed AR, le Grange C, et al. Adaptation and crosscultural validation of the United States Primary Care Assessment Tool (expanded version) for use in South Africa. Afr J Prim Health Care Fam Med 2015;7:e1-e11.

26. Dullie L, Meland E, Hetlevik $\varnothing$, et al. Development and validation of a Malawian version of the primary care assessment tool. BMC Fam Pract 2018;19:63.

27. Starfield B. Primary care: balancing health needs, services, and technology (Rev. ed. New York: Oxford University Press, 1998.

28. Aoki T, Inoue M, Nakayama T. Development and validation of the Japanese version of Primary Care Assessment Tool. Fam Pract 2016;33:112-7.

29. Macinko J, Almeida C, de Sá PK. A rapid assessment methodology for the evaluation of primary care organization and performance in Brazil. Health Policy Plan 2007;22:167-77.

30. Wroe EB, Dunbar EL, Kalanga N, et al. Delivering comprehensive HIV services across the HIV care continuum: a comparative analysis of survival and progress towards 90-90-90 in rural Malawi. BMJ Glob Health 2018;3:e000552.

31. Mays GP, Smith SA. Evidence links increases in public health spending to declines in preventable deaths. Health Aff 2011;30:1585-93.

32. Bein MA, Unlucan D, Olowu G, et al. Healthcare spending and health outcomes: evidence from selected East African countries. Afr Health Sci 2017; 17:247-54.

33. Makaula P, Bloch P, Banda HT, et al. Primary Health Care in rural Malawi - a qualitative assessment exploring the relevance of the community-directed interventions approach. BMC Health Serv Res 2012;12:328.

34. Kristjansson E, Hogg W, Dahrouge S, et al. Predictors of relational continuity in primary care: patient, provider and practice factors. BMC Fam Pract 2013;14:72.

35. World Health Organization. Arguing for universal health coverage. Geneva: WHO, 2013.

36. Kringos DS, Boerma WG, Hutchinson A, et al. The breadth of primary care: a systematic literature review of its core dimensions. BMC Health Serv Res 2010;10:65.

37. Hogg W, Rowan M, Russell G, et al. Framework for primary care organizations: the importance of a structural domain. Int J Qual Health Care 2008;20:308-13. 